\title{
ALTERAÇÕES FISIOLÓGICAS E BIOQUÍMICAS DURANTE O ARMAZENAMENTO DE SEMENTES DE Tabebuia serratifolia
}

\author{
Débora Gabriela Silva ${ }^{1}$, Maria Laene Moreira de Carvalho², Marcela Carlota Nery³, \\ Luciana Magda de Oliveira ${ }^{4}$, Carla Massimo Caldeira ${ }^{5}$
}

(recebido: 15 de outubro de 2009; aceito: 27 de setembro de 2010)

\begin{abstract}
RESUMO: A espécie Tabebuia serratifolia (ipê-amarelo) é utilizada para reflorestamento de áreas degradadas, além de possuir propriedades medicinais e madeireiras. Sua propagação é por sementes, as quais podem apresentar problemas de conservação, como alterações no seu potencial fisiológico ao longo do armazenamento. Para investigar a ocorrência dessas alterações fisiológicas e bioquímicas de sementes de ipê-amarelo, durante o armazenamento sob condições de câmara fria e ambiente, foram realizadas avaliações trimestrais da germinação, viabilidade, vigor, teor de água, de polifenóis e proteínas resistentes ao calor, em sementes armazenadas por doze meses. Para sementes armazenadas em câmara fria foram observados resultados superiores de germinação e vigor quando comparados com os obtidos na condição ambiente. Ocorreram decréscimos nos teores de polifenóis ao longo do armazenamento, já as proteínas resistentes ao calor mantiveram a mesma intensidade de bandas. Na condição ambiente, a germinação torna-se nula aos nove meses; enquanto que, em câmara fria, as sementes permanecem viáveis durante 12 meses de armazenamento.
\end{abstract}

Palavras-chave: Ipê-amarelo, Handroanthus serratifolius, longevidade.

\section{PHYSIOLOGICAL AND BIOCHEMICAL PROPERTIES CHANGES DURING STORAGE OF Tabebuia serratifolia SEEDS}

\begin{abstract}
The species Tabebuia serratifolia (ipe amarelo) is used for reclamation of degraded areas, in addition it possess medicinal and timber properties. Its propagation is by seeds, which present problems of conservation, as changes in the percentage of germination throughout the storage. To investigate the possible changes in some physiological and biochemistry behaviors of "ipê-amarelo" seeds during the storage the germination, viability, vigor, protein content of resistant to heat and polyphenols were evaluated. The seeds were stored under environmental and cold chamber conditions for 12 months. Evaluations were made every 3 months. For seeds stored in cold chamber higher germination and vigor were observed as compared to the environmental condition. There were decreases in the levels of polyphenols during storage, but the heat shock proteins kept the same intensity of bands. In the environmental condition the germination becomes null on the $9^{\text {th }}$ month, while in cold chamber the seeds remain viable during the 12 months of storage.
\end{abstract}

Key words: Yellow-ipe, Handroanthus serratifolius, longevity.

\section{INTRODUÇAO}

A espécie Tabebuia serratifolia Vahl Nich., conhecida como ipê-amarelo, é encontrada em várias regiões do Brasil (CARVALHO, 1994), mas a sua exploração indiscriminada tem levado à diminuição de populações dessa espécie. O ipê-amarelo, considerado árvore símbolo do Brasil, pode ser utilizado no reflorestamento de áreas degradadas e na ornamentação, além de possuir propriedades medicinais (VIDAL-TESSIER, 1988).
O armazenamento de sementes de espécies florestais ameaçadas, como T. serratifolia, é importante para a conservação de germoplasma de populações e para a produção de mudas em diferentes épocas do ano.

Em estudos sobre armazenamento de sementes de espécies do gênero Tabebuia, observaram-se variações na porcentagem de germinação caracterizada por uma reduzida germinação após a colheita seguida de decréscimos e acréscimos (FIGLIOLIA et al., 1988; KAGEYAMA et al., 1992; OLIVEIRA, 2004).

\footnotetext{
${ }^{1}$ Engenheira Agrônoma, Especialista Florestal - Rua General Carneiro, 683, Centro - 18300-260 - Capão Bonito, SP - debora.gabriela@fibria.com.br ${ }^{2}$ Engenheira Agrônoma, Professora Dra. em Agronomia - Departamento de Agricultura/DAG - Universidade Federal de Lavras/UFLA - Cx. P. 3037 37200-000 - Lavras, MG - mlaenemc@ufla.dag.br

${ }^{3}$ EngenheiraAgrônoma, Professora Dra. emAgronomia-Departamento deAgronomia - Universidade Federal dos Vales do Jequitinhonha e Mucuri/UFVJMCampus JK - Rodovia MGT 367, Km 583, nº 5000 - Alto da Jacuba - Diamantina, MG - nery.marcela@gmail.com

${ }^{4}$ Engenheira Florestal, Professora Dra. em Fitotecnia/Sementes - Departamento de Engenharia Florestal-Universidade do Estado de Santa Catarina/UDESCAv. Luis de Camões, 2090 - 88520-000 - Lages, SC - luciana@cav.udesc.br

${ }^{5}$ Doutoranda em Agronomia - Departamento Agricultura/DAG - Universidade Federal de Lavras/UFLA - Cx. P. 3037 - $37200-000$ - Lavras, MG carlaufla@yahoo.com.br
} 
Essa variação também pode ser observada quando as sementes são submetidas ao envelhecimento artificial, como observado por Gemaque (1999) em T. impetiginosa e Oliveira (2004) em T. serratifolia.

As variações de respostas na germinação de sementes durante o armazenamento podem ser explicadas, dentre outros fatores, pela dormência de sementes ou mesmo por reações fisiológicas e bioquímicas (CHUNJIE et al., 2002; MYCOCK; BERJAK, 1995). Entretanto, segundo Oliveira (2004), tratamentos de superação de dormência em lotes de sementes de $T$. serratifolia, armazenadas ou envelhecidas artificialmente, não ocasionam aumento na germinação, evidenciando a ausência de dormência e indicando que outros fatores podem afetar a germinação ao longo do armazenamento.

Dentre esses fatores, tem sido relatado que compostos fenólicos, como floridizim, ácido salicílido, ácido clorogênico e cumarina, presentes no tegumento de sementes podem atuar como inibidores de germinação, por consumirem oxigênio durante os processos de oxidação (BEWLEY; BLACK, 1994). Segundo Santos et al. (1991), a presença de compostos fenólicos diminui com o armazenamento das sementes, devido à sua oxidação. Oliveira (2004) observou que o envelhecimento artificial por 72 horas de sementes de $T$. serratifolia reduziu o conteúdo de fenóis e aumentou a germinação. Outro fator que pode causar alterações na germinação de sementes durante o armazenamento é a presença de proteínas, como as proteínas resistentes ao calor, que podem se expressar sob condições de estresse (VIERLING, 1991). Algumas proteínas resistentes ao calor atuam como "chaperone" molecular, que são definidas como proteínas que vinculam e estabilizam uma conformação instável de outra proteína (HENDRICK; HARTL, 1985).

Portanto, as sementes podem apresentar alterações fisiológicas e bioquímicas, decorrentes das condições ambientais durante o armazenamento, como a umidade relativa do ar e temperatura do ambiente de conservação.

Objetivou-se, com esta pesquisa, investigar a ocorrência de alterações fisiológicas e bioquímicas em sementes de Tabebuia serratifolia ao longo do armazenamento, sob diferentes condições.

\section{MATERIAL E MÉTODOS}

Utilizaram-se sementes coletadas de seis matrizes de T. serratifolia, localizadas próximo ao Campus da Universidade Federal de Lavras, MG. As sementes foram beneficiadas manualmente, sendo excluídas, por análise visual, as sementes vazias. Foram armazenadas em sacos de polietileno, em condições ambiente de laboratório e em câmara fria $\left(8^{\circ} \mathrm{C} \pm 4^{\circ} \mathrm{C}\right.$ e $46 \%$ de umidade relativa). Durante a condução dos experimentos, houve variações na temperatura e umidade relativa do armazenamento em ambiente, que inicialmente era de $22,5^{\circ} \mathrm{C}$ e $80 \%$ de umidade relativa e atingiu $16,9^{\circ} \mathrm{C}$ e $61 \%$ de umidade relativa, aos 12 meses.

As sementes armazenadas nas diferentes condições a zero, três, seis, nove e 12 meses foram avaliadas em sua germinação, índice de velocidade de germinação, viabilidade pelo teste de tetrazólio, grau de umidade, polifenóis e proteínas resistentes ao calor.

No teste de germinação, as sementes foram acondicionadas em caixas gerbox com substrato areia lavada e autoclavada, sob luz constante a $30^{\circ} \mathrm{C}$. Utilizaramse oito repetições de 25 sementes. As contagens foram realizadas diariamente, a partir da protrusão radicular para se computar o índice de velocidade de germinação (IVG) (MAGUIRE, 1962). As avaliações de plântulas normais foram realizadas aos 14 dias (primeira contagem) e 28 dias após semeadura.

Para o teste de tetrazólio, o tegumento das sementes foi retirado após embebição, entre papéis, por 12 horas a $30^{\circ} \mathrm{C}$, e os embriões foram submersos em $0,5 \%$ de solução de tetrazólio a $30^{\circ} \mathrm{C}$, por 12 horas. Em seguida, os embriões foram cortados no sentido longitudinal, e avaliados de acordo com a coloração dos tecidos, extensão dos danos e aspectos dos tecidos e classificadas em viáveis ou inviáveis, conforme Oliveira (2004).

$\mathrm{Na}$ avaliação física foi determinado o grau de umidade das sementes. Para essa determinação foram utilizadas quatro repetições de um grama de sementes, que foram pesadas e submetidas à estufa a $105^{\circ} \mathrm{C} \pm 2^{\circ} \mathrm{C}$ por 24 horas (BRASIL, 1992).

Bioquimicamente, para a determinação de polifenóis as sementes de $T$. serratifolia foram submetidas à estufa de circulação forçada de ar a $60^{\circ} \mathrm{C}$ por 72 horas e moídas em moinho refrigerado. Os fenóis contidos nas sementes foram extraídos pelo método de Goldstein e Wail (1963), utilizando-se como extrator metanol 80\% e a identificação efetuada de acordo com o método FollinDenis descrito pela Association of Official Analitical Chemists - AOAC (1990).

$\mathrm{Na}$ determinação de proteínas resistentes ao calor, $100 \mathrm{mg}$ das sementes, moídas por um minuto na presença de nitrogênio líquido, foram colocadas em microtubos com 1,8 mL de tampão de extração e agitadas em Vortex.

Cerne, Lavras, v. 17, n. 1, p. 1-7, jan./mar. 2011 
O homogeneizado foi centrifugado a 14.000 g por 20 minutos a $4^{\circ} \mathrm{C}$ e o sobrenadante incubado em banho-maria a $80^{\circ} \mathrm{C}$, por 10 minutos e novamente centrifugado. A corrida eletroforética foi realizada em gel de poliacrilamida SDSPAGE a 12,5\% (gel separador) e $6 \%$ (gel concentrador) a $100 \mathrm{~V}$, por seis horas. Antes da aplicação no gel, os tubos de amostras, contendo $100 \mu \mathrm{L}$ de extrato $+57 \mu \mathrm{L}$ de solução tampão da amostra foram mantidos em banho-maria com água em ebulição por cinco minutos (BLACKMAN et al., 1991). Os géis foram corados em coomassie blue a $0,05 \%$, durante 18 horas e descorados em solução de ácido acético 10\% (ALFENAS et al., 1991).

Realizou-se, o experimento, em delineamento inteiramente casualizado, em parcelas subdivididas no tempo, sendo duas condições de armazenamento (ambiente e câmara fria) e cinco épocas de armazenamento (zero, três, seis, nove e 12 meses). Os dados obtidos foram comparados pelo teste de médias, a $5 \%$ de probabilidade e submetidos à análise de regressão polinomial. Dados de grau de umidade foram transformados por logaritmo neperiano (ln) e para os demais testes utilizou-se a transformação $\sqrt{ } \mathrm{x}$, por meio do programa estatístico Sisvar (FERREIRA, 1999).

\section{RESULTADOS E DISCUSSÃO}

O grau de umidade das sementes de $T$. serratifolia, que inicialmente estava em $6 \%$, sofreu alterações ao longo do armazenamento (Figura 1). Em condições de

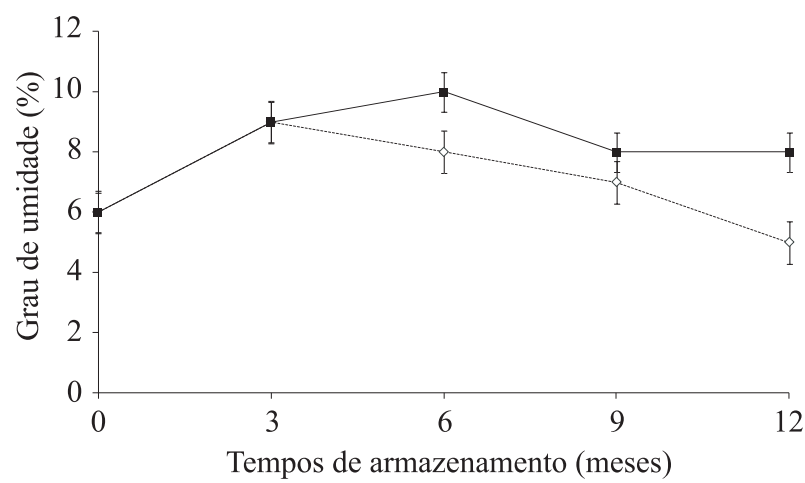

$$
\cdots \cdots \quad a m b=6,278571+0,772619 x-0,073413 x^{2} \quad R^{2}=90,45 \%
$$

$$
\rightarrow \mathrm{cf}=0,000000+5,111111 \mathrm{x}-0,777778 \mathrm{x}^{2}+0,033951 \mathrm{x}^{3} \quad \mathrm{R}^{2}=100 \%
$$

Figura 1 - Grau de umidade das sementes de Tabebuia serratifolia, ao longo do armazenamento em condição ambiente e em câmara fria.

Figure 1-Moisture content of Tabebuia serratifolia seeds during environmental and cold chamber storage conditions. câmara fria houve acréscimos, atingindo $10 \%$ aos seis meses e $8 \%$ ao final do armazenamento. Na condição ambiente, houve acréscimos no grau de umidade até três meses, quando houve redução, alcançando no final do período de armazenamento $5 \%$. Os valores observados no grau de umidade das sementes de $T$. serratifolia durante o armazenamento são, segundo Miyasaki e Cândido (1978), os ideais para a conservação de sementes desse gênero; visto que, por serem ortodoxas, teores de água menores causam diminuição da atividade metabólica das sementes, o que prolonga sua viabilidade. Para T. chrysotricha, Martins et al. (2009) observaram que a conservação das sementes é favorecida pelo armazenamento com teores de água em torno de $11,9 \%$.

De acordo com a curva ajustada para germinação, observa-se que as sementes armazenadas em câmara fria mantiveram seu potencial de germinação durante todo o período de armazenamento; enquanto que, as armazenadas em ambiente sofreram uma queda brusca na germinação, tendo seu potencial de germinação nulo aos nove meses de armazenamento (Figura 2). Esses resultados estão de acordo com o que se observa para sementes ortodoxas: quanto maior a temperatura e a umidade no armazenamento, maior será a atividade fisiológica da semente e mais rápida sua deterioração (OLIVEIRA, 2007; SCHMIDT, 2000).

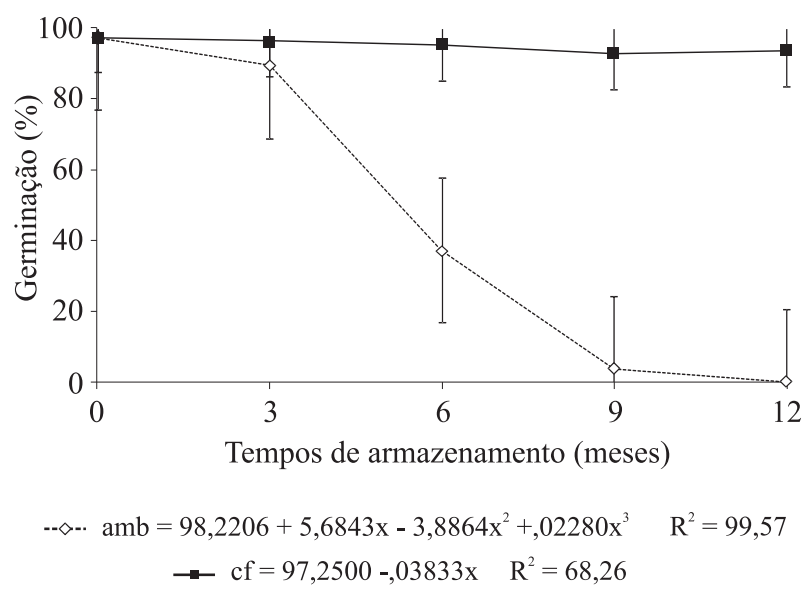

Figura 2 - Porcentagens de germinação das sementes de Tabebuia serratifolia, ao longo do armazenamento em condição ambiente e em câmara fria.

Figure 2 - Percentage of germination of Tabebuia serratifolia seeds during environmental and cold chamber storage conditions.

Cerne, Lavras, v. 17, n. 1, p. 1-7, jan./mar. 2011 
Resultados semelhantes foram obtidos para sementes de Tabebuia impetiginosa (SOUZA et al., 1980), T. heptaphylla (KAGEYAMA et al., 1992), T. heterophylla (SILVA et al., 2001), T. aurea (CABRAL et al., 2003) e T. serratifolia (SOUZA et al., 2005), em que a capacidade germinativa das sementes foi melhor conservada em câmara fria. Já Oliveira (2004) observou decréscimos na germinação de sementes de $T$. serratifolia quando submetidas ao armazenamento em câmara fria por 12 meses, o que não ocorreu com sementes de T. impetiginosa, que apresentaram oscilações na porcentagem de germinação, nas mesmas condições ambientais e períodos de armazenamento.

$\mathrm{Na}$ primeira contagem da germinação, para as sementes armazenadas em câmara fria, houve decréscimo na porcentagem de plântulas normais aos três meses seguido de acréscimo e decréscimo até os 12 meses de armazenamento. Já para as sementes armazenadas na condição ambiente, a redução na porcentagem de germinação foi contínua, tornandose nula aos nove meses de armazenamento (Figura 3).

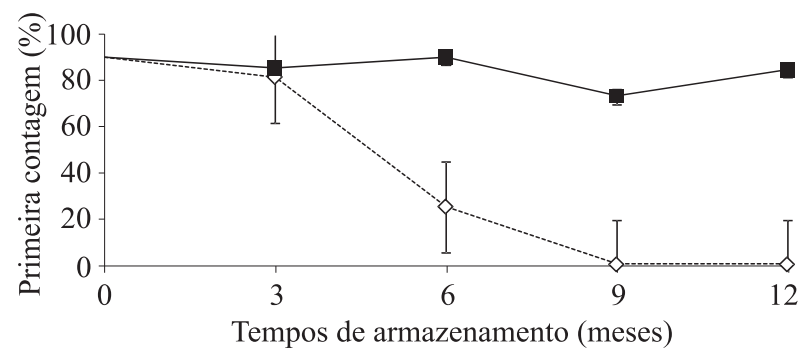

$--\diamond-\mathrm{amb}=91,786232+3,551731 \mathrm{x}-3,531804 \mathrm{x}^{2}+0,217279 \mathrm{x}^{3} \quad \mathrm{R}^{2}=98,48 \%$ $\rightarrow \mathrm{cf}=9,500000+43,074074 \mathrm{x}-6,800926 \mathrm{x}^{2}+0,311214 \mathrm{x}^{3} \quad \mathrm{R}^{2}=100 \%$

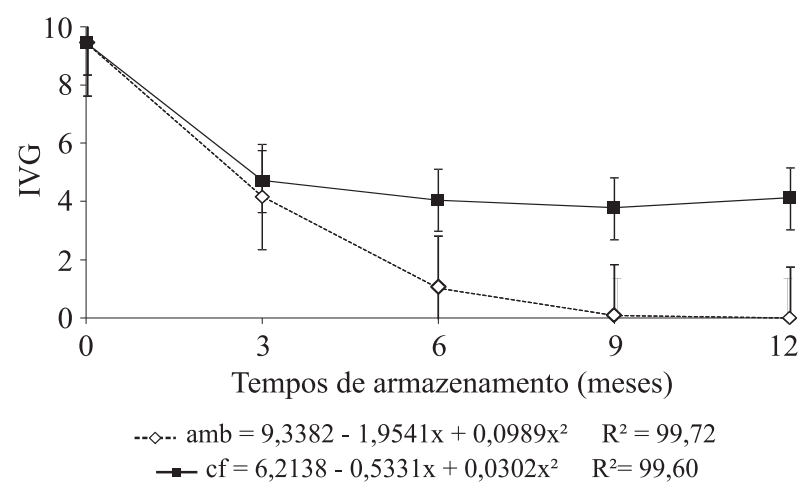

Figura 3 - Porcentagens de plântulas normais de Tabebuia serratifolia obtidas nos testes de primeira contagem de germinação e IVG, ao longo do armazenamento em condição ambiente e em câmara fria.

Figure 3-Percentage of Tabebuia serratifolia seedlings in the first count and IGS during normal and cold chamber storage conditions.
Os dados de IVG ajustaram-se ao modelo quadrático para ambas as condições de armazenamento (Figura 3). No armazenamento em câmara fria, houve queda acentuada até os três meses, seguido de uma estabilidade até os 12 meses de armazenamento. Para sementes armazenadas em ambiente também foi observado decréscimo do índice de velocidade de germinação desde o início do armazenamento. Esses resultados comprovam que a perda de vigor das sementes precede à perda da viabilidade. Segundo Marcos Filho (2005), o termo vigor surgiu para identificar manifestações do comportamento das sementes em campo ou durante o armazenamento; comportamento que, muitas vezes, não é identificado pelo teste de germinação.

Souza et al. (2005) também observaram redução no IVG de sementes de T. serratifolia armazenadas em condições ambientais com decréscimos ao longo do período. Segundo Borba Filho e Perez (2009), alterações no vigor de sementes das espécies $T$. roseo-alba e $T$. impetiginosa são primeiramente identificadas pela redução da velocidade de germinação.

Aos dados obtidos pelo teste de tetrazólio, ajustaram-se equações de regressão de efeito cúbico para condição ambiente de armazenamento e quadrático para armazenamento em câmara fria (Figura 4). Na condição ambiente observa-se decréscimo na viabilidade das sementes a partir dos três meses de armazenamento. No armazenamento em câmara fria esse decréscimo foi menos acentuado, ou seja, a partir do sexto mês a viabilidade das sementes não sofreu redução até o final do armazenamento, resultado que coincide com o observado na primeira contagem de germinação.

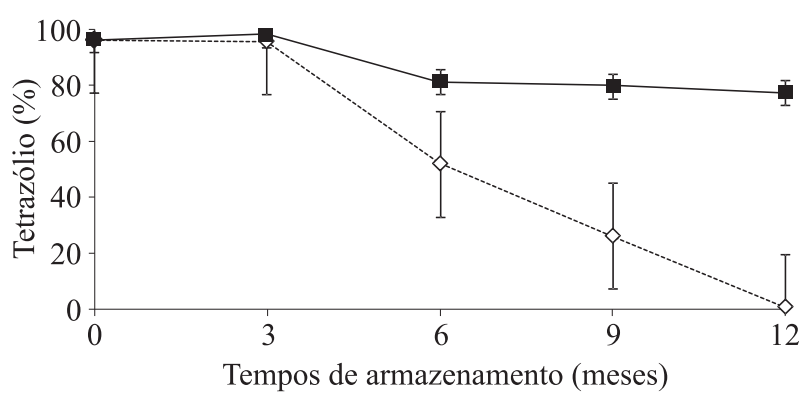

$--\diamond-a m b=97,228571+1,797619 x-0,948413 x^{2}+0,055556 x^{3} \quad R^{2}=90,52 \%$ $\rightarrow \mathrm{cf}=144,875-18,125 \mathrm{x}+0,513889 \mathrm{x}^{2} \quad \mathrm{R}^{2}=99,69 \%$

Figura 4 - Porcentagens de sementes viáveis de Tabebuia serratifolia no teste de tetrazólio, ao longo do armazenamento em condição ambiente e em câmara fria.

Figure 4 - Percentage of Tabebuia serratifolia seeds viability according to the tetrazolium test during environmental and cold chamber storage conditions.

Cerne, Lavras, v. 17, n. 1, p. 1-7, jan./mar. 2011 
Observou-se redução de viabilidade nas sementes armazenadas em condição ambiente aos nove meses de armazenamento; enquanto que, pelo teste de germinação no mesmo período, a viabilidade é nula. Esses resultados confirmam o que foi descrito por Centro Agronómico Tropical de Investigación y Enseñanza - CATIE (2000), que o teste de tetrazólio avalia somente o embrião, sem levar em consideração as influências das estruturas externas das sementes que podem influenciar na germinação, podendo apresentar resultados superiores, principalmente por não apresentar barreiras ou transmitir microrganismos que possam afetar o desenvolvimento de plântulas.

Durante o armazenamento, ocorreram decréscimos nos teores de polifenóis para ambas as condições ao longo do armazenamento, exceto para sementes armazenadas por 12 meses em câmara fria (Figura 5).

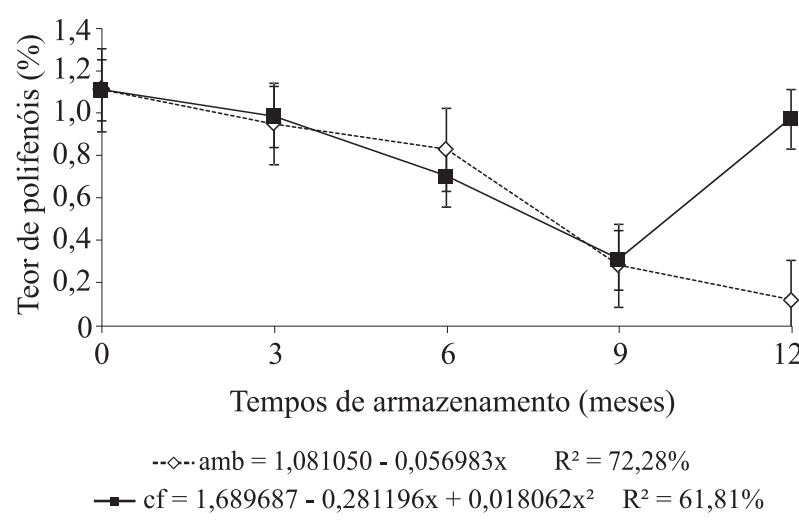

Figura 5 - Teores de polifenóis em sementes de Tabebuia serratifolia, ao longo do armazenamento em condição ambiente e em câmara fria.

Figure 5 - Polyphenol content of Tabebuia serratifolia seeds in environmental and cold chamber storage conditions.

Esses resultados coincidem com os encontrados por Santos et al. (1991), que relataram o decréscimo de compostos fenólicos durante o armazenamento de sorgo sacarino, ressaltando que essa diminuição ocorre, geralmente, com o processo de maturação e durante os primeiros anos de armazenamento, devido à sua oxidação. Carvalho et al. (2008) relataram reduções nos teores de polifenóis de sementes de Tabebuia serratifolia, durante a maturação. Enquanto que Oliveira (2004) observou que em envelhecimento acelerado por até 96 horas, sementes de $T$. serratifolia e T. impetiginosa, não apresentaram alterações significativas nos teores de polifenóis.
Pelo perfil eletroforético de proteínas resistentes ao calor (Figura 6), pode ser observada a presença de bandas em sementes de T. serratifolia nos diferentes períodos e condições de armazenamento. É evidente a ausência de bandas, na parte superior do zimograma e a presença de bandas de baixo peso molecular, ao redor de $10 \mathrm{kDa}$ em todos os tratamentos. No entanto, as condições e o período de armazenamento não afetaram o perfil eletroforético de proteínas resistentes ao calor.

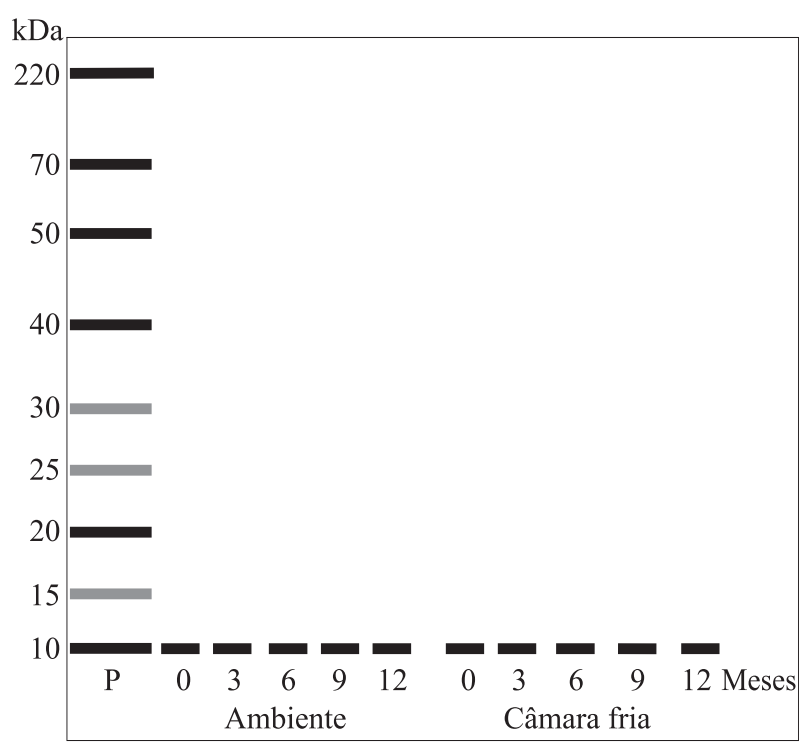

Figura 6 - Perfil eletroforético de proteínas resistentes ao calor de sementes de Tabebuia serratifolia, ao longo do armazenamento em condição ambiente e em câmara fria.

Figure 6 - Electrophoretic profile of heat-resistant proteins of Tabebuia serratifolia seeds during environmental and cold chamber storage conditions.

Desta forma, sementes de Tabebuia serratifolia com $6 \%$ de umidade e $100 \%$ de germinação inicial, mantêm-se viáveis por 12 meses, quando armazenadas em câmara fria $\left(8^{\circ} \mathrm{C} \pm 4^{\circ} \mathrm{C}\right.$ e $46 \%$ de umidade relativa), já quando são armazenadas em condição ambiental, sujeitas às variações nos teores de água e temperatura, a germinação torna-se nula aos nove meses. Os teores de polifenóis sofreram redução contínua durante o armazenamento na condição ambiente, sendo que, em câmara fria foi observada redução até nove meses seguida por um acréscimo aos 12 meses de armazenamento. Os teores de proteínas resistentes ao calor permaneceram constantes nas duas condições de armazenamento.

Cerne, Lavras, v. 17, n. 1, p. 1-7, jan./mar. 2011 


\section{REFERÊNCIAS}

ALFENAS, A. C.; PETERS, I.; BRUCE, W.; PASSADOS, G. C. Eletroforese de proteínas e isoenzimas de fungos e essências florestais. Viçosa, MG: UFV, 1991. 242 p.

ASSOCIATION OF OFFICIAL ANALITICAL CHEMISTS. Methods of the association of official analitical chemists. Washington, 1990. $684 \mathrm{p}$.

BEWLEY, J. D.; BLACK, M. Seeds: physiology of development and germination. New York: Plenum, 1994. $445 \mathrm{p}$.

BLACKMAN, S. A.; WETTLAUFER, S. H.; OBENDORF, R. L.; LEOPOLD, A. C. Maturation proteins associated with desiccation tolerance in soybean. Plant Physiology, Rockville, v. 96, n. 3, p. 868-874, July 1991.

BORBA FILHO, A. B.; PEREZ, S. C. J. G. A.

Armazenamento de sementes de ipê-branco e ipê-roxo em diferentes embalagens e ambientes. Revista Brasileira de Sementes, Brasília, v. 31, n. 1, p. 259-269, 2009.

BRASIL. Ministério da Agricultura e Reforma Agrária. Regras para análise de sementes. Brasília: SNDA/DNDV/ CLAV, 1992. 365 p.

CABRAL, E. L.; BARBOSA, D. C. de A.; SIMABUKURO, E. A. Armazenamento e germinação de sementes de Tabebuia áurea (Manso) Benth. \& Hook. F. Ex. S. Moore. Acta Botânica Brasileira, São Paulo, v. 17, n. 4, p. 609-617, 2003.

CARVALHO, M. L. M. de; NERY, M. C.; OLIVEIRA, L. M.; HILHORST, H. W. M.; GUIMARÃES, R. M. Morphophysiological development of Tabeluia serratifolia Vahl Nich. seeds. Scientia Agricola, Piracicaba, v. 65, n. 6, p. 643-651, 2008.

CARVALHO, P. E. R. Espécies florestais brasileira: recomendações silviculturais, potencialidades e uso da madeira. Colombo: EMBRAPA/CNPF, 1994. 640 p.

\section{CENTRO AGRONÓMICO TROPICAL DE}

INVESTIGACIÓN Y ENSEÑANZA. Proyecto de semillas

forestales: laboratorio para analizar de 2000 a 5000 muestras de semillas. Turrialba, 2000. 99 p. (Serie técnica, manual técnico, 37).
CHUNJIE, L.; YANRONG, W.; TINGHENG, Z.; LING, Y. Response of alfafa seed to stress storage conditions. Yingyong-Shengtai-Xuebao, Lanzhou, v. 13, n. 8, p. 957961, 2002.

FERREIRA, D. F. SISVAR 4. 3 - Sistema de Analises Estatísticas. Lavras: UFLA, 1999.

FIGLIOLIA, M. B.; SILVA, A.; JARDIM, D. C. P.; IWANE, M. S. S. Viabilidade de sementes liofilizadas de essências florestais nativas. Silvicultura em São Paulo, São Paulo, v. 20/22, p. 47-55, 1988.

GEMAQUE, R. C. R. Maturação, tolerância à dessecação e alterações na qualidade fisiológica em sementes de ipêroxo (Tabebuia impetiginosa (Mart.) Standl.) envelhecidas artificialmente. 1999. 93 p. Dissertação (Mestrado em Ciências Florestais) - Universidade Federal de Lavras, Lavras, 1999.

GOLDSTEIN, J. L.; WAIL, T. Changes in tannin in ripening fruits. Phytochemistry, Oxford, v. 2, n. 4, p. 371-382, 1963.

HENDRICK, J. P.; HARTL, F. U. The role of molecular chaperones in protein folding. The FASEB Journal, v. 9, p. 1559-1569, 1995.

KAGEYAMA, P. Y.; SANCHEZ, S. P. A.; FERRAZ, E. M.; SOUZA, L. M. C. Armazenamento de sementes de três espécies nativas (Tabebuia heptaphylla, Erytrhina verna e Chorisia speciosa). Revista do Instituto Florestal, São Paulo, v. 4, p. 435-439, 1992.

MAGUIRE, J. D. Seed of germination, aid in selection and evaluation for seedling emergence and vigor. Crop Science, Madison, v. 2, p. 176-177, 1962.

MARCOS FILHO, J. Fisiologia de sementes de plantas cultivadas. Piracicaba: FEALQ, 2005. 495 p.

MARTINS, L.; LAGO, A. A.; SALES, W. R. M. Conservação de sementes de ipê-amarelo (Tabebuia chrysotricha (Mart. ex A. DC.) Standl.) em função do teor de água das sementes e da temperatura do armazenamento. Revista Brasileira de Sementes, Brasília, v. 31, n. 2, p. 86-95, 2009.

MIYASAKI, J. M.; CÂNDIDO, J. F. Secagem de sementes de ipê amarelo (Tabebuia serratifolia Vall/Don). Seiva, v. 38, n. 85, p. 12-17, 1978.

Cerne, Lavras, v. 17, n. 1, p. 1-7, jan./mar. 2011 
MYCOCK, D. J.; BERJAK, P. The implication of seedassociated mycoflora during storage. In: KIGEL, J.; GALILI, G. Seed development and germination. New York: M. Dekker, 1995. p. 747-766.

OLIVEIRA, L. M. Avaliação da qualidade de semente de Tabebiua serratifolia Vahl Nich. E Tabebuia impetiginosa (Martius Ex A. P. De Candolle Standley) envelhecidas natural e artificialmente. 2004. 160 p. Tese (Doutorado em Fitotecnia) - Universidade Federal de Lavras, Lavras, 2004.

OLIVEIRA, O. S. Tecnologia de sementes florestais. Curitiba: UFPR, 2007. 185 p.

SANTOS, D. S. B.; TILLNAM, M. A. A.; PETERS, J. A. Presença de inibidores e efeito de glumas na embebição de sementes de sorgo sacarino. Pesquisa Agropecuária Brasileira, Brasília, v. 26, n. 7, p. 989-993, jul. 1991.

SCHMIDT, L. Guide to handling of tropical and subtropical forest seed. Danida: Forest Seed Centre, 2000. $511 \mathrm{p}$.
SILVA, A. da; FIGLIOLIA, M. B.; AGUIAR, I. B.; PERECIN, D. Liofilização e armazenamento de sementes de ipê-rosa (Tabebuia heterophylla (A.P. Cabdolle) Britton) Bignoniaceae. Revista Brasileira de Sementes, Brasília, v. 23, n. 1, p. 252-259, 2001.

SOUZA, S. M.; PIRES, I. E.; LIMA, P. C. F. Influência da embalagem e condições de armazenamento na longevidade de sementes florestais. In: Pesquisa florestal no nordeste semi-árido: sementes e mudas. Petrolina: EmbrapaCPTSA, 1980. p. 15-24. (Boletim de pesquisa, 2).

SOUZA, V. C.; BRUNO, R. L. A.; ANDRADE, L. A. Vigor de sementes armazenadas de ipê amarelo Tabebuia serratifolia (Vahl.) Nich. Revista Árvore, Viçosa, v. 29, n. 6, p. 833-841, 2005.

VIDAL-TESSIER, A. M. Sur de quiñónez lipophiles du bois de tronc de Tabebuia serratifoilia (Vahl.) Nichols. Annales Pharmaceutiques Françaises, Paris, v. 46, n. 1, p. 55-57, 1988.

VIERLING, E. The role of heat shock proteins in plants. Annual Review of Plant Physiology and Plant Molecular Biology, Palo Alto, v. 42, p. 579-620, 1991. 